\title{
Heterochronic opsin expression due to early light deprivation results in drastically shifted visual sensitivity in a cichlid fish: Possible role of thyroid hormone signaling
}

\author{
Nidal Karagic $^{1}$ iD | Andreas Härer ${ }^{1}$ (D) | Axel Meyer ${ }^{1,2}$ iD | Julián Torres-Dowdall1,3 iD
}

\author{
${ }^{1}$ Zoology and Evolutionary Biology, Department \\ of Biology, University of Konstanz, Konstanz, \\ Germany \\ ${ }^{2}$ Radcliffe Institute for Advanced Study, Harvard \\ University, Cambridge, Massachusetts \\ ${ }^{3}$ Zukunftskolleg, University of \\ Konstanz, Konstanz, Germany \\ Correspondence \\ Julián Torres-Dowdall, Zoology and Evolutionary \\ Biology, Department of Biology, University of \\ Konstanz, Konstanz 78457, Germany. \\ Email: julian.torres-dowdall@uni-konstanz.de \\ Funding information \\ Deutsche Forschungsgemeinschaft, \\ Grant/Award Number: TO 914/2-1; H2020 Euro- \\ pean Research Council, Grant/Award Number: \\ 293700 “GenAdap"; Young Scholar Fund of the \\ University of Konstanz, Grant/Award Number: \\ FP 794/15
}

\begin{abstract}
During early ontogeny, visual opsin gene expression in cichlids is influenced by prevailing light regimen. Red light, for example, leads to an early switch from the expression of short-wavelength sensitive to long-wavelength sensitive opsins. Here, we address the influence of light deprivation on opsin expression. Individuals reared in constant darkness during the first 14 days post-hatching (dph) showed a general developmental delay compared with fish reared under a 12:12 hr lightdark cycle (control group). Several characters including pigmentation patterns and eye development, appeared later in dark-reared individuals. Quantitative real-time PCR and fluorescent in situ hybridization at six time points during the 14 days period revealed that fish from the control group expressed opsin genes from $5 \mathrm{dph}$ on and maintained a short-wavelength sensitive phenotype (sws1, rh2b, and rh2a). Onset of opsin expression in dark-reared Midas cichlids was delayed by 4 days and visual sensitivity rapidly progressed toward a long-wavelength sensitive phenotype (sws $2 b$, rh2a, and Iws). Shifts in visual sensitivities toward longer wavelengths are mediated by thyroid hormone (TH) in many vertebrates. Compared to control fish, dark-reared individuals showed elevated dio3 expression levels - a validated proxy for TH concentration - suggesting higher circulating TH levels. Despite decelerated overall development, ontogeny of opsin gene expression was accelerated, resulting in retinae with long-wavelength shifted predicted sensitivities compared to light-reared individuals. Indirect evidence suggests that this was due to altered TH metabolism.

KEYWORDS

Amphilophus astorquii, dio3, dark-rearing, development, Midas cichlid, ontogeny
\end{abstract}

\section{INTRODUCTION}

Development is often buffered from variation in environmental conditions, at least when these are within the normal range commonly experienced during the evolutionary history of species (Gilbert, 2001, Siegal \& Bergman, 2002; West-Eberhard, 2003). However, when environmental perturbations exceed this range, development might be altered in ways that adversely impact fitness (Blas, Bortolotti, Tella, Baos, \& Marchant, 2007; Ghalambor, McKay, Carroll, \& Reznick, 2007; Rutherford, 2000). One such extreme perturbation is the modification of the circadian rhythm by depriving individuals of light. Rearing animals under constant darkness can result in developmental instability, causing reductions in growth rate, malformations, and even increased levels of mortality (Barlow, Pearce, Rodgers, \& Clayton, 1995; Liu, Stickney, Dickhoff, \& McCaughran, 1994; Trotter, Battaglene, \& Pankhurst, 2003; Villamizar, García-Alcazar, \& SánchezVázquez, 2009; Villamizar et al., 2011). The visual system, in particular, is expected to be highly impacted by light deprivation, both on a short-term (ontogenetic change) and a long-term (evolutionary change) scale (Kröger \& Fernald, 1994; Langecker, Schmale, \& Wilkens, 1993; Tobler, Coleman, Perkins, \& Rosenthal, 2010). Hubel and Wiesel were among the first to recognize that visual experience can influence the development of the visual system from experiments on cats (Hubel \& Wiesel, 1963; Hubel \& Wiesel, 1970; Wiesel \& Hubel, 1963). Since this seminal work, the generality of their findings was confirmed in a number of different species. For example, surface dwelling fish reared in constant darkness tend to develop myopias due to deformations of the eye (Kröger et al., 1994) and abnormalities of the optic tectum and the retina (Blaxter, 1970). Similar patterns have been identified in terrestrial animals when light deprived (Fagiolini, Pizzorusso, Berardi, Domenici, \& Maffei, 1994; Gottlieb, Fugate-Wentzek, \& Wallman, 1987; Guyton, Greene, \& Scholz, 1989; Norton, Amedo, \& Siegwart, 2006).

The impact of light deprivation on a long-term evolutionary scale can be observed in the eyes of animals living in aphotic or almost aphotic environments. For example, animals living in completely dark 
caves often show reduction or complete loss of eyes (Behrmann-Godel, Nolte, Kreiselmaier, Berka, \& Freyhof, 2017; Jeffery, 2005; Schobert et al., 2013; Wilkens, Strecker, \& Yager, 1989), whereas adaptations to dim-light conditions, as experienced by deep sea organisms, include the enlargement of eyes, the presence of a reflective tapetum lucidum, and a high density of enlarged photoreceptors (Busserolles, Marshall, \& Collin, 2014; Claes et al., 2014). Thus, the significance of light is evident on an individual and a species level.

Visual pigments in retinal photoreceptors differ characteristically between organisms adapted to light rich versus dim or completely dark environments (Yokoyama, 2008). Visual pigments are composed of a photosensitive molecule, a retinal chromophore, covalently bound to a transmembrane G-protein-coupled receptor, the opsin protein (Wald, 1968). The spectral and kinetic characteristics of visual pigments are known to be dependent on the amino acid sequence of the opsin proteins (e.g., Yokoyama, 2008). For example, amino acid replacements at particular residues of rhodopsin, which codes for the protein component of dim-light sensitive visual pigments, cause spectral (e.g., Nagai et al., 2010; Sugawara et al., 2005; Yokoyama, 2008) and kinetic (e.g., Sugawara, Imai, Nikaido, Imamoto, \& Okada, 2010) adaptations to the dim-light environment of deep water. In more extreme environments, as in aphotic caves, rhodopsin can accumulate nonsynonymous substitutions due to relaxed selection that negatively impact the structure of the protein, sometimes resulting in the loss of functionality (Niemiller, Fitzpatrick, Shah, Schmitz, \& Near, 2013). However, in other cases, the protein remains functional and there is regulatory, rather than structural divergence across populations. For example, cave dwelling populations of fish (e.g., Poecilia mexicana) show heritable reductions in expression levels when compared to closely related surface populations (Tobler et al., 2010). These patterns of divergence are thought to evolve over long periods of time, either as a result of selection (e.g., Jeffery, 2005; Sugawara et al., 2005) or due to neutral accumulation of degenerative mutations (Niemiller et al., 2013). Thus, it is likely that an aphotic environment induces evolutionary changes as those observed in P. mexicana (Tobler et al., 2010) and ultimately results in complete degeneration of the visual system as seen in the blind cichlid Lamprologus lethops (Schobert et al., 2013). Yet, the developmental consequences of rearing surface dwelling organisms under dark conditions for opsin expression are still poorly understood. Here, we ask if visual stimuli are required for the normal development of opsin expression patterns and what are the consequences of rearing organisms in complete darkness.

Opsin expression patterns are known to be susceptible to variation in light conditions, especially during development (Dalton, Lu, Leips, Cronin, \& Carleton, 2015; Fuller, Carleton, Fadool, Spady, \& Travis, 2005; Härer, Torres-Dowdall, \& Meyer, 2017; Hofmann, O' Quin, Smith, \& Carleton, 2010; Novales Flamarique, 2013; Sakai, Ohtsuki, Kasagi, Kawamura, \& Kawata, 2016; Wagner and Kröger, 2005). For instance, teleost fish reared in murky environments where short wavelength light is rapidly scattered by suspended particles, or in red light enriched environments, have opsin expression patterns resulting in visual sensitivities shifted toward longer wavelengths (Fuller et al., 2005; Härer et al., 2017). Likewise, visual sensitivity shifted toward shorter wavelengths is observed when fish are reared in environments enriched in blue light (Härer et al., 2017). Thus, it is expected that light deprivation during development results in altered opsin expression patterns; but, to our knowledge, the consequences of photic deprivation for opsin expression during development have not been explored. In this study, we investigate whether opsin expression is affected by light deprivation in the Midas cichlid, Amphilophus astorquii, a species we have previously shown to be developmentally plastic in response to light conditions as described above (Härer et al., 2017).

Midas cichlids, like other cichlids, have eight opsin genes expressed in two types of photoreceptor cells, one is rod-specific for dim-light vision, and seven are expressed cone-specifically for color vision (Carleton, Dalton, Escobar-Camacho, \& Nandamuri, 2016; Yokoyama, 2008). The high number of cone opsin genes found in cichlids is attributed to multiple gene duplication events within two spectral classes, the medium-wavelength sensitive rh2 and short-wavelength sensitive sws2 (Carleton \& Kocher, 2001; Rennison, Owens, \& Taylor, 2012). There are two types of cone photoreceptors in the retina of cichlid fish, single and double cones (Fernald, 1981), which are organized in a square cone mosaic pattern over the whole retina (Levine, MacNichol, Kraft, \& Collins, 1979). Single cones express the shortwavelength sensitive opsins (i.e., sws 1 , sws $2 b$, and sws $2 a ; \lambda_{\max }=360$, 425 , and $456 \mathrm{~nm}$, respectively), whereas double cones express the medium wavelength sensitive $r h 2$ opsins (i.e., rh2b, rh2a 2 , and rh2a ; $\lambda_{\max }=472,517$, and $527 \mathrm{~nm}$ ) and the long-wavelength sensitive opsin (i.e., Iws; $\lambda_{\max }=560 \mathrm{~nm}$ ) (peaks of maximum absorbance from Torres-Dowdall et al., 2017). Despite having a repertoire of eight opsin genes, cichlids usually express a subset of three cone opsins at a given time; often a short-wavelength sensitive (sws1, rh2b, rh2a), a mediumwavelength sensitive (sws $2 b, r h 2 b, r h 2 a$ ) or a long-wavelength sensitive set (sws2a, rh2a, Iws) (Carleton et al., 2016). Most cichlids show ontogenetic changes in opsin expression, with a short-wavelength sensitive set being commonly expressed very early in ontogeny (during the first weeks after hatching), shifting to middle-wavelength sensitivity as juveniles and ultimately changing to a long-wavelength sensitive set in sexually mature individuals (Carleton et al., 2008, 2016; Härer et al., 2017; O'Quin, Smith, Sharma, \& Carleton, 2011a; Spady et al., 2006). This common pattern of expressing three cone opsins at the same time can be affected by the prevailing light conditions. In light-deprived environments, overexpression of one cone opsin might improve achromatic vision at the cost of color discrimination (Chiao, Vorobyev, Cronin, \& Osorio, 2000; Cronin, Johnsen, Marshall, \& Warrant, 2014), as it might be the case for Midas cichlids in Lake Nicaragua (Torres-Dowdall et al., 2017). In fact, in the narrow light environment experienced by deep sea fish, cone opsin gene expression is almost exclusively restricted to $r h 2 a$, which is similar to $r h 1$ ( $\lambda_{\max }=$ $497 \mathrm{~nm}$ ) in spectral sensitivity (de Busserolles et al., 2017a; Pointer, Carvalho, Cowing, Bowmaker, \& Hunt, 2007; Yokoyama, Zhang, Radlwimmer, \& Blow, 1999), and in turbid dim-light environments /ws is the dominant opsin (e.g., Torres-Dowdall et al., 2017).

It is still unclear how opsin expression is regulated, although there have been important contributions toward this end (Carleton et al., 2010, 2016; O'Quin et al., 2011b, 2012). There is evidence that thyroid hormone (TH) has strong effects on opsin expression patterns (Cheng \& Novales Flamarique, 2004; Glaschke et al., 2011; Ng et al., 
2001; Raine \& Hawryshyn, 2009; Roberts, Srinivas, Forrest, de Escobar, \& Reh, 2006; Suliman \& Novales Flamarique, 2014). In many organisms, including Midas cichlids, visual sensitivity of the retina is correlated with TH levels (indirectly measured using deiodinases as proxies) and artificially manipulating $\mathrm{TH}$ levels affects the pattern of cone opsin expression (Cheng, Gan, \& Novales Flamarique, 2009; Härer et al., 2017; Novales Flamarique, 2013). During development, artificially increasing circulating $\mathrm{TH}$ levels often results in a premature shift of visual sensitivity toward long wavelengths by changing the expression from short- to long-wavelength sensitive opsin genes (Cheng et al., 2009; Härer et al., 2017; Novales Flamarique, 2013). Prolonged periods of darkness affect TH metabolism in different organisms (Bedolla \& Torre, 2011; Yasuo et al., 2005) and disruption of circadian rhythms affects the production of melatonin, which is involved in the development of thyroid follicles (Falcón, 1999; Falcón, Migaud, Muñoz-Cueto, \& Carrillo, 2010). Moreover, light deprivation has negative impacts on the expression of TH-receptors in the retina of vertebrates (Martino, Seo, Lernmark, \& Refetoff, 1980). Thus, it is possible that dark-rearing affects visual sensitivities indirectly through its effects on TH metabolism.

Our goal was to examine the pattern of opsin expression in photoreceptor cells when they are deprived of photic input to elucidate the role of light on expression patterns. The two main questions we wanted to answer are: (1) Does light induce opsin gene expression per se? or (2) Does light rather modulate which opsin genes are expressed across retinae? To address these questions, we investigated changes in opsin gene expression during early development of Midas cichlids in response to ambient light conditions. Given current knowledge on the effect of dark-rearing (Villamizar et al., 2011), it is expected that darkreared Midas cichlids will show decelerated development compared with individuals experiencing normal light conditions, as it has been shown for other fish species (Villamizar et al., 2009). On one hand, the eye could suffer morphological malformations (e.g., Kröger et al., 1994) and retinal photoreceptors could be impaired by reducing or eliminating opsin expression. On the other hand, expression of particular opsin genes might be favored, for example, it is possible that opsin expression is adaptively plastic in dark-reared fish, resulting in the upregulation of the expression of dim-light vision mediating rhodopsin (rh1) and overexpression of one cone opsin gene (e.g., rh2 or Iws), as this is known to be an adaptation to dark environments as found in deep sea fish or fish from turbid environments (Pointer et al., 2007; Yokoyama et al., 1999).

\section{METHODS}

\subsection{Study species}

Astorqui's Midas cichlid, A. astorquii (from now on, the Midas cichlid), is an endemic species in the small (five species) and young (less than 2,000 generations) Midas cichlid adaptive radiation of crater lake Apoyo in Nicaragua (Kautt, Machado-Schiaffino, \& Meyer, 2016). Nicaraguan crater lakes, like Lake Apoyo, have been recently colonized by Midas cichlids from the great Lakes Nicaragua and Managua, making it possible to infer the ancestral phenotype from that observed in great lake species today (Barluenga, Stölting, Salzburger, Muschick, \& Meyer, 2006; Kautt et al., 2016). Within this crater lake, Midas cichlids, including this particular species, have evolved a mediumwavelength sensitive visual system, mainly by modifying the ancestral pattern of opsin gene expression (Torres-Dowdall et al., 2017). This is most likely an adaptation to the blue-shifted light environment of the clear and deep crater lake Apoyo (Härer et al., 2017; Torres-Dowdall et al., 2017). We previously demonstrated pronounced developmental plasticity in opsin gene expression as a response to different light environments (Härer et al., 2017), but it is not clear how complete darkness affects opsin gene expression in this species.

\subsection{Rearing conditions}

Two days post fertilization during the prehatching stage (Kratochwil, Sefton, \& Meyer, 2015), embryos of one brood were divided into two different light treatments. One group was reared in a 12:12 hr lightdark cycle (LD, control treatment) under broad spectrum light (warmwhite treatment from Härer et al. (2017); for irradiance measurements in the two treatments see Supp. Figure 1), and another in constant darkness (DD, experimental treatment). Every day at 11:00 am, three individuals from both treatments were photographed. The individuals that were photographed to document developmental progression were excluded from further analyses to avoid effects of short-term exposure to intense light.

\subsection{Analysis of gene expression}

Gene expression levels were measured at six different time points for each treatment. We collected samples from both treatments at $3,5,7,9,11$, and 14 days post-hatching (dph; $n=6$, respectively). Individuals were euthanized with an overdose of tricaine methanesulfonate (MS-222) and stored at $-20^{\circ} \mathrm{C}$ in RNAlater (Sigma-Aldrich, St. Louis, Missouri, USA) until RNA extraction. RNA was extracted from whole embryos using the RNeasy Mini kit (Qiagen, Hilden, Germany). Total RNA was quantified with a Colibri Microvolume Spectrometer (Titertek Berthold, Pforzheim, Germany) and RNA quality was determined by electrophoresis with a $1 \%$ agarose gel. We reverse transcribed 500 ng RNA per sample with a first-strand cDNA synthesis kit (GoScript ${ }^{\mathrm{TM}}$ Reverse Transcription System; Promega, Madison, Wisconsin, USA) and determined relative gene expression levels with quantitative real-time PCR (RT-qPCR). Amplification and quantification were performed for seven opsin genes (rh1, sws1, sws2b, sws2a, rh2b, rh2a, Iws; Torres-Dowdall et al., 2017) and two housekeeping genes (inositol monophosphatase 2, imp2, and lactate dehydrogenase, Idh2), using the GoTaq ${ }^{\circledR}$ qPCR Master Mix (Promega, Madison, Wisconsin, USA) and the CFX96 ${ }^{\mathrm{TM}}$ Real-Time System (Bio-Rad, Hercules, California, USA). The rh2a paralog rh2a $\alpha$ was disregarded for the analysis, since previous results showed that its expression is consistently below $1 \%$ of total rh2a expression in Midas cichlids (Torres-Dowdall et al., 2017).

We examined the expression of genes involved in TH metabolism, since directly measuring $\mathrm{TH}$ levels in Midas cichlids during the first 
weeks post hatching is not possible due to low plasma volumes (Härer et al., 2017). Commonly used proxies for TH levels are TH converting deiodinases (García-G, Jeziorski, Valverde-R, \& Orozco, 2004; Härer et al., 2017; Johnson \& Lema, 2011; Marlatt et al., 2012; Walpita, Crawford, Janssens, der Geyten, \& Darras, 2009). Deiodinase 2 (dio2) is a locally acting enzyme converting inactive $T_{4}$ into the active $T_{3}$ form and deiodinase 3 (dio3) is responsible for the inactivation of $T_{3}$ (Gereben, Zeöld, Dentice, Salvatore, \& Bianco, 2008b; Johnson et al., 2011). Importantly, circulating $T_{3}$ levels have been shown to downregulate dio 2 and to upregulate dio3 expression levels in teleost fish (Härer et al., 2017; Johnson et al., 2011; Marlatt et al., 2012).

Gene expression levels were normalized to the geometric mean of the two housekeeping genes. Relative expression levels $E_{\mathrm{i}}$ were calculated using the equation,

$$
E_{\mathrm{i}}=2^{\left(C_{\mathrm{tgm}}-C_{\mathrm{ti}}\right)}
$$

with $C_{\text {tgm }}$ being the geometric mean of the critical cycle numbers of the housekeeping genes and $C_{t i}$ the critical cycle number of the gene of interest. To compare differences in gene expression between age and treatment, as well as to test for effects of the interaction of these two factors for each gene, we used a nonparametric equivalent to a two-way ANOVA, the Sheirer-Ray-Hare test (Scheirer, Ray, \& Hare, 1976).

Predicted sensitivities were calculated to visualize distinct phenotypes. We calculated predicted sensitivities as in Hofmann et al. (2009) using the Midas cichlid peaks of absorbance for sws $2 b$, sws $2 a$, rh2b, rh2a, and Iws from Torres-Dowdall et al. (2017). The peak of absorbance for sws 1 was used from Oreochromis niloticus (Spady et al., 2006), as it has not been empirically determined for Midas cichlids or other Neotropical cichlids. For single and double cones, we separately calculated and analyzed predicted sensitivities. Previous studies have shown that extraocular expression of visual opsin genes occurs (Shao et al., 2017), which might influence the calculation of predicted visual sensitivities. However, the strong congruence between expression values for the examined opsin genes from RT-qPCR (Figure 3) and in situ hybridization (Figure 4B) suggests a minute proportion of extraocular opsin gene expression, if present at all. Given that no opsin expression was detected until $9 \mathrm{dph}$ in DD individuals (see section Results: Onset of cone opsin expression is delayed, but ontogenetic progression of expression is accelerated in a dark-environment), we estimated visual sensitivities for both treatment groups only at 9,11 , and $14 \mathrm{dph}$. Statistical analyses for predicted sensitivities were performed as described for RT-qPCR results.

\subsection{In situ hybridization}

For LD and DD individuals, we performed triple fluorescent in situ hybridization (FISH) 7 and $14 \mathrm{dph}(n=5$, respectively) as previously described (Torres-Dowdall et al., 2017; Woltering et al., 2009). Individuals were euthanized using an overdose of MS-222 and eyes were rapidly enucleated. We dissected retinae and fixed them in $4 \%$ paraformaldehyde in phosphate buffered saline overnight at $4^{\circ} \mathrm{C}$. Retinae were probed using either probes for double cone opsin genes ( $r h 2 b$, rh2a, Iws) or single cone opsin genes (sws1, sws $2 b$, sws $2 a$ ). The examined opsin genes show enough sequence divergence to make crossreactivity between probes unlikely (Torres-Dowdall et al., 2017). Additionally, as pointed above, the congruence between expression levels for opsin genes from RT-qPCR (Figure 3) and in situ hybridization (Figure $4 B$ ), in addition to visual inspections of fluorescence signals (Supp. Figure 2) support the specificity of the used probes. Fluorescence and differential interference contrast (DIC) images were obtained using a Leica DM6B microscope. To quantify cone identities, we superimposed a grid of six parallel and equally spaced transects over images of the whole retinae and counted all cells along the transects. To compare morphological characteristics of cone cells between the treatment groups, we measured diameters and densities of single and double cones, respectively. For double cone diameter, the length of the separating membrane was measured. Cone densities were calculated from the total number of cells along transects and given as number of cells per $100 \mu \mathrm{m}$. To compare percentages of cone identities, we used a nonparametric multiresponse permutation procedure, commonly used to analyze non-normally distributed proportional data as in this case (Mielke, Berry, Brockwell, \& Williams, 1981). Differences in cone diameter and density between treatments were compared using $t$-tests.

\section{RESULTS}

\subsection{Development is decelerated in dark-reared Midas cichlids}

Midas cichlids reared under a 12:12 hr LD cycle showed a developmental progression as previously described by Kratochwil et al. (2015). Compared to LD individuals, specimens reared in constant darkness (DD) showed a developmental delay that increased with time (Figure 1). Traits typically seen in LD individuals at 3,5 , and $7 \mathrm{dph}$ appeared at 5,9 , and $14 \mathrm{dph}$ in DD individuals, respectively (Figure 1). For example, pigmentation of the eye with melanophores was complete $5 \mathrm{dph}$ in DD individuals, but at $3 \mathrm{dph}$ in LD individuals. Pigmentation with iridiophores occurred at $9 \mathrm{dph}$ in DD individuals, but at $5 \mathrm{dph}$ in LD individuals. The pronounced fin fold vascularization, normally disappearing $5 \mathrm{dph}$ in developing individuals, persisted until $9 \mathrm{dph}$ in DD individuals. Additionally, morphological malformations arose during the development of DD individuals. Most distinguishable was an unnatural curvature of the spine that became more pronounced with time (Figure 1).

\subsection{Expression of rh1 is delayed and downregulated in dark-reared Midas cichlids}

LD individuals started expressing rh1 at $5 \mathrm{dph}$, but in DD individuals expression was delayed until $9 \mathrm{dph}$ (Figure 2). From then on, expression of rh1 gradually increased with age in both treatments (Figure 2). Overall rh1 expression was affected by light treatment as DD individuals expressed less rh1 than LD individuals throughout ontogeny, but rh1 expression progressed similarly in both treatments (Figure 2). 
A
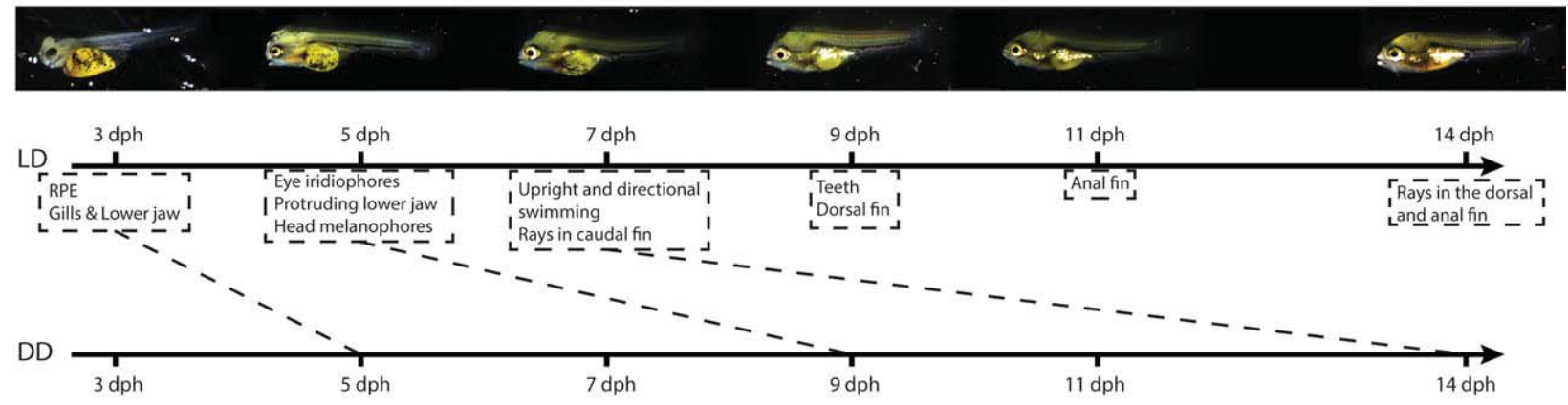

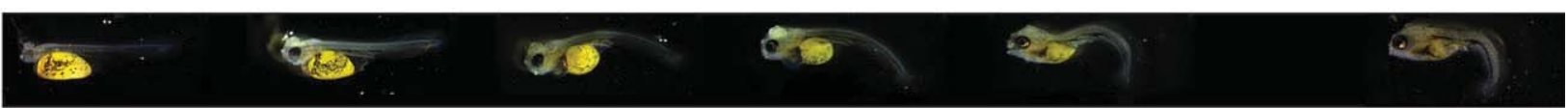

B
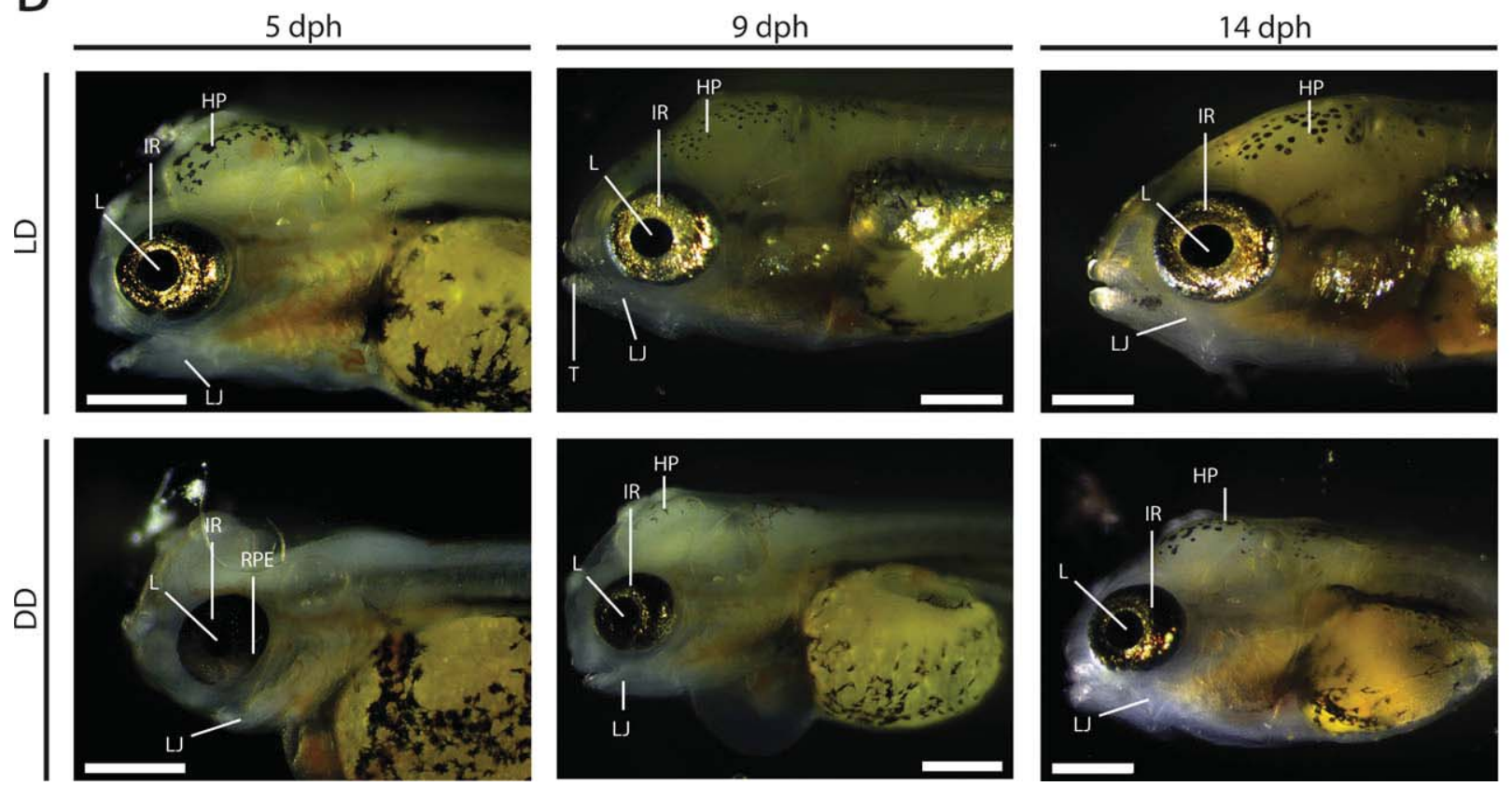

FIGURE 1 Description of development for Midas cichlids reared under white light (LD) or in darkness (DD). (A) Illustration of the development at each time point of sampling, depicted on timelines. Dashed lines connect the developmental stages of Midas cichlids from the different treatments. (B) Detailed comparison of LD and DD individuals at 5, 9 and $14 \mathrm{dph}$. Abbreviations: L, lens; IR, iridiophores; HP, head pigmentation; LJ, lower jaw; RPE, retinal pigment epithelium. Scale bar $=500 \mu \mathrm{m}$ [Color figure can be viewed at wileyonlinelibrary.com]

\subsection{Onset of cone opsin expression is delayed, but ontogenetic progression of expression is accelerated in dark-reared Midas cichlids}

Cone opsin gene expression was first evident at $5 \mathrm{dph}$ in LD individuals. Throughout the experiment, LD individuals expressed mainly sws 1 in single cones and $r h 2 a$ and $r h 2 b$ in double cones, although Iws was detected at low levels throughout development (Figures 3 and $4 \mathrm{~A}$ and $4 B)$. In contrast, cone opsin gene expression in DD individuals was delayed until $9 \mathrm{dph}$. From 9 to $11 \mathrm{dph}$, sws 1 was the dominant opsin in single cones, but at $14 \mathrm{dph}$ expression of the violet-sensitive sws $2 b$ increased in expression to about the same level and a few DD individuals even expressed the blue-sensitive sws $2 a$ at this age (i.e., significant age $\times$ treatment interaction for sws $2 b$ and sws $2 a$; Figures 3 and $4 \mathrm{~A}$ and B). As a result of this change in expression pattern, sensitivity of single cones rapidly progressed toward longer wavelengths in DD individuals compared to LD individuals (i.e., significant age $\times$ treatment interaction; Figure 5A). The double cone opsin genes rh2 $b$, rh2a, and Iws were all expressed at low levels in $9 \mathrm{dph} D D$ individuals (Figures 3 and $4 A$ and $4 B$ ). Across time points, Iws expression was similar in DD and LD individuals, whereas $r h 2 b$ was reduced in DD individuals across all ages (Figure 3). Even though overall rh2a expression level was lower in DD compared to LD individuals, this difference appeared to decrease, or even disappear, with age (although the interaction term was not significant; Figure 3). The differential usage of $r h 2 b$ and Iws between LD and DD individuals was particularly evident when considering double cone spectral class in FISH (Figures $4 \mathrm{~A}$ and $4 \mathrm{~B}$ ). This resulted in the 


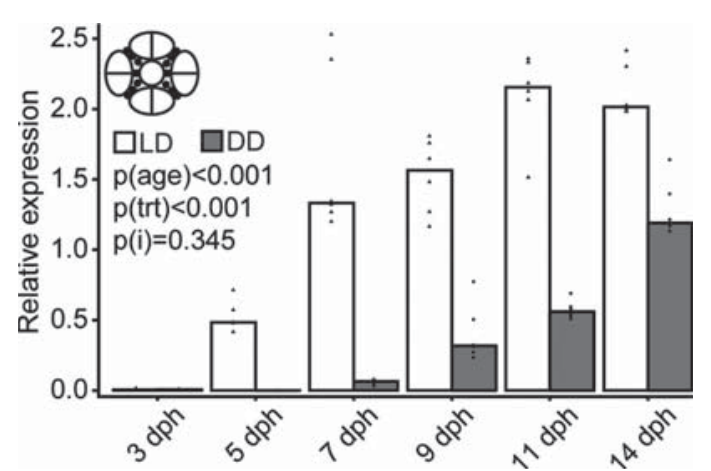

FIGURE 2 Expression of rhodopsin rh1. Expression levels of rh1 in rods for the six sampling time points and both treatments ( $n=6$, respectively). Relative expression is normalized to the geometric mean of two housekeeping genes. Individual values are given with bars showing the median for each time point per treatment. Schematic representation of a cone rosette with gray rods in between, indicating the cell type expressing rh1

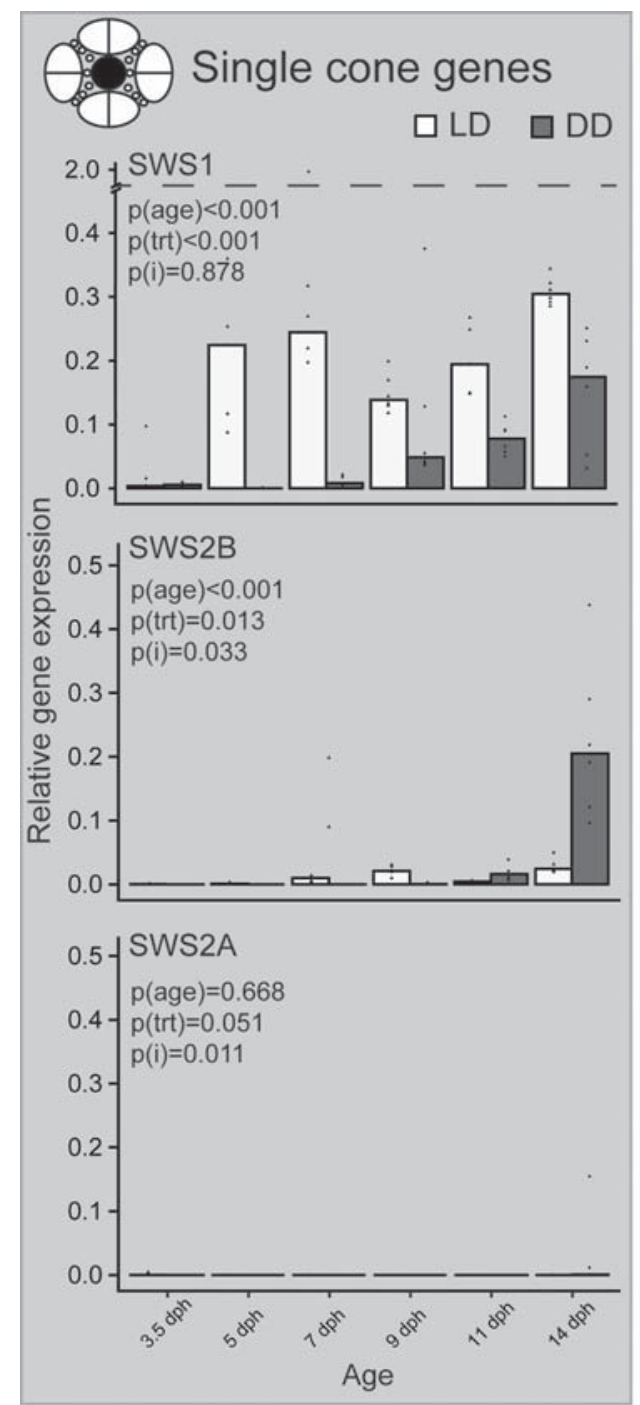

predicted sensitivities for double cones for DD individuals being significantly shifted toward longer wavelengths compared to LD individuals across all ages (Figure 5B).

\subsection{Double cone density is reduced in dark-reared Midas cichlids}

We measured diameter ( $n=30$ per individual for single and double cones respectively) and density of cones from triple FISH fluorescence images for LD and DD $14 \mathrm{dph}$ individuals ( $n=5$ per treatment; Figure 4C). Density was calculated as number of cones along the same transects used to identify cone identities and is given as number of cells per $100 \mu \mathrm{m}$. The only measure affected by dark-rearing was the density of double cones, which was significantly lower in DD individuals (Figure 4C). Single cone density and diameter of both cone types did not differ between treatments (Figure 4C).

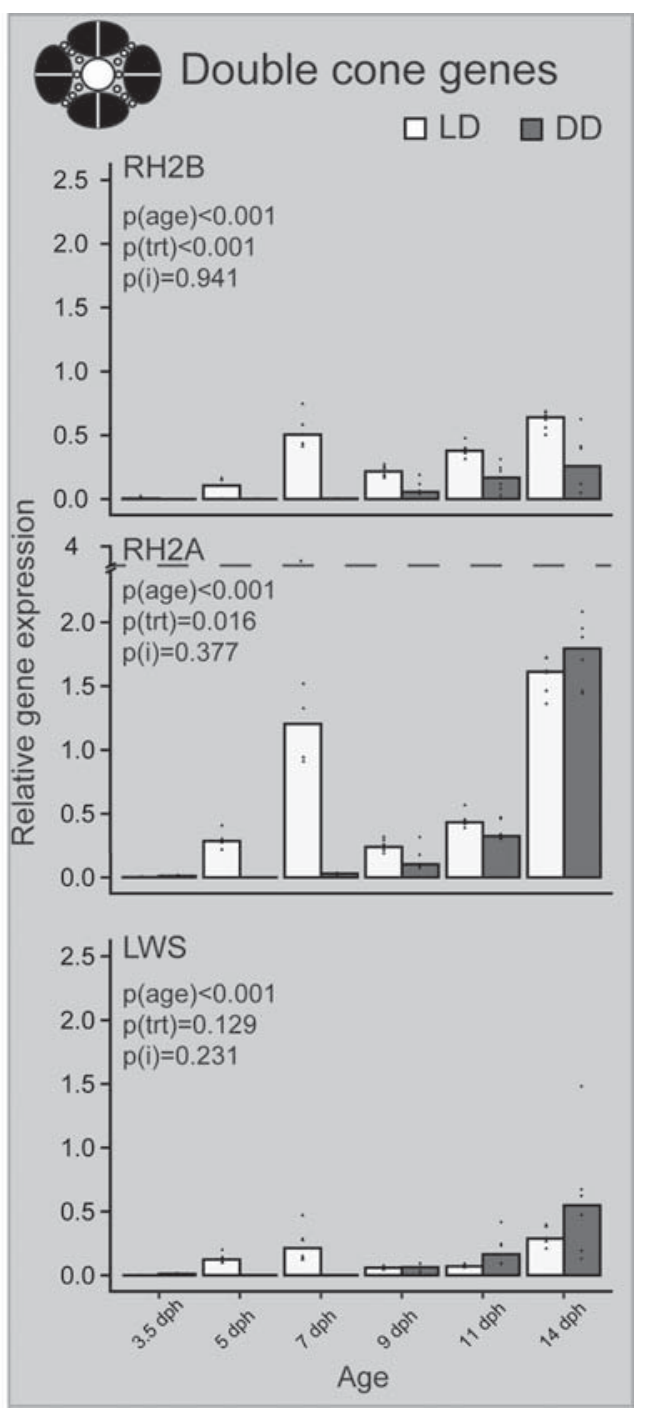

FIGURE 3 Cone opsin gene expression. Expression levels for the six cone opsin genes normalized to the geometric mean of two housekeeping genes $(\mathrm{n}=6$ ). Single cone opsin genes sws1, sws $2 b$, and sws $2 a$ (left panel) and double cone opsin genes rh $2 b$, rh2a, and lws (right panel). Individual values are given with bars indicating the median for each gene. Schematic representation of a cone rosette with gray cones, indicating the cone type expressing the examined opsin genes 
A

A

등
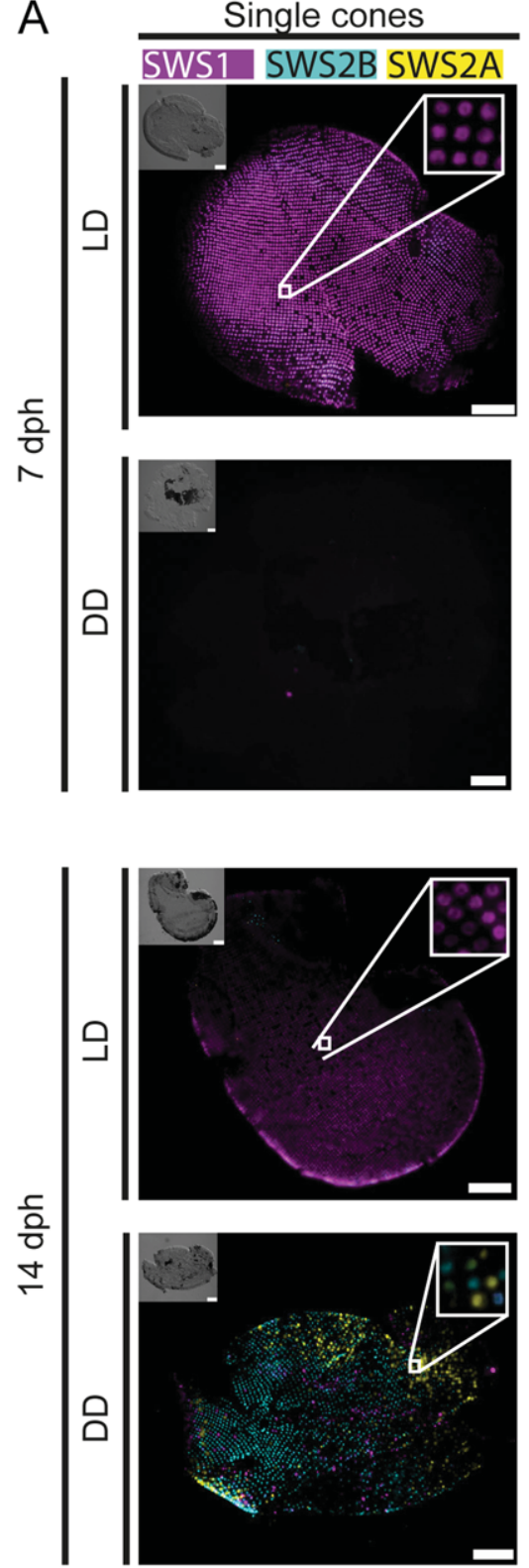

Double cones
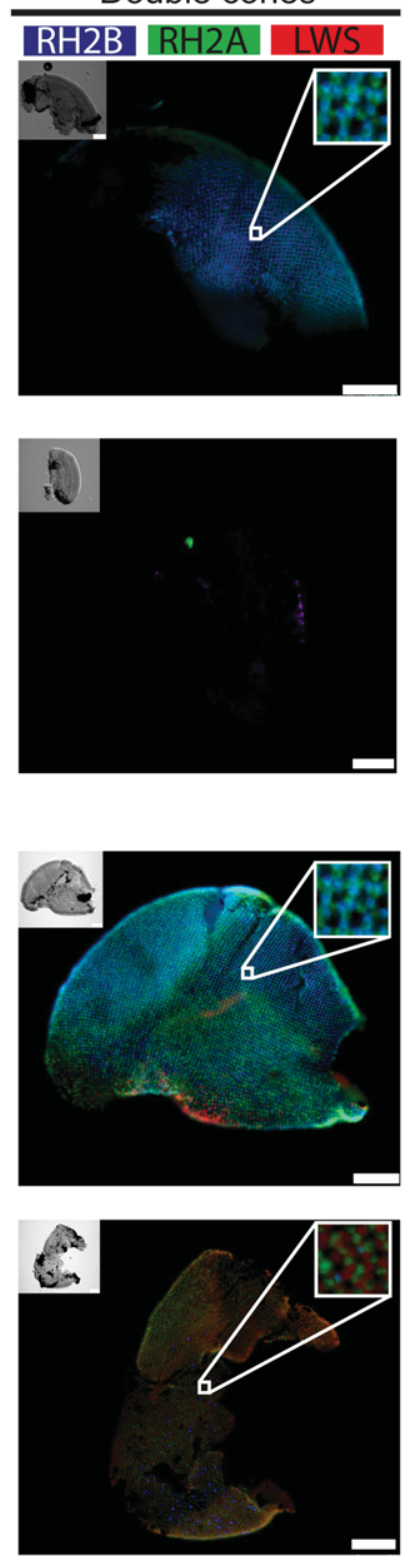
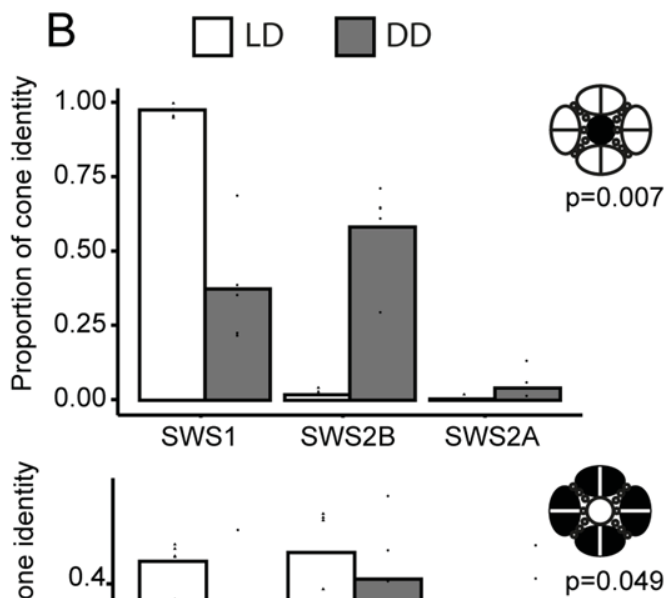

$\mathrm{p}=0.049$
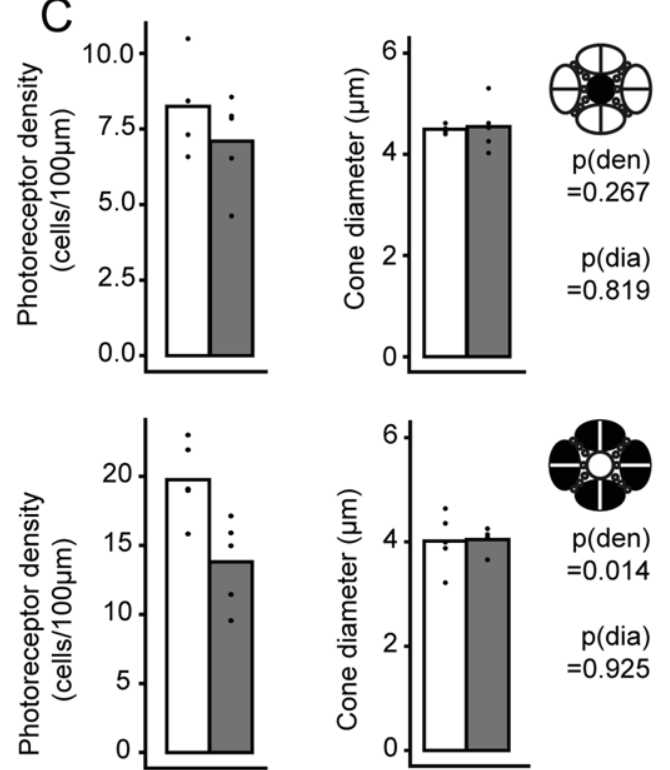

FIGURE 4 (A) Triple fluorescent in situ hybridization on LD and DD Midas cichlids' retinae at 7 and $14 \mathrm{dph}$. Retinae were probed with either a combination of the single cone opsin genes sws 1 , sws $2 b$, and sws $2 a$ or double cone opsin genes rh $2 b$, rh $2 a$, and lws. Differential interference contrast (DIC) pictures are shown embedded in the corresponding picture. Scale bar $=100 \mu \mathrm{m}$. For each retina, a $40 \times$ magnification image of the cellular structure is shown. (B) We analyzed proportions of cone identities at $14 \mathrm{dph}$. Percentages of cones expressing single cone opsin genes (upper panel) or double cone opsin genes (lower panel) $(n=5)$. (C) Morphological analysis of retinal structure for single (upper panel) and double (lower panel) cones. Densities were calculated as the mean from the number of cones along six parallel transects over the whole retina, and are given as the number of cells along $100 \mu \mathrm{m}$ of a transect. For double cones, the diameter was measured along the separating membrane ( $n=5$; significance for cell density $(P($ den $))$ and diameter $(P($ dia $))$ are given in for each cone type, respectively) [Color figure can be viewed at wileyonlinelibrary.com]

\subsection{TH signaling is disrupted in dark-reared Midas cichlids}

Expression levels of dio2 were not affected by dark-rearing (Figure 6). On the other hand, dio3 expression levels were significantly higher in DD individuals compared to LD individuals (Figure 6). The differential expression of dio3 between treatments indicates that dark-rearing disrupts normal TH pathways, potentially resulting in increased circulating $T_{3}$ levels.

\section{DISCUSSION}

In the absence of light, development of Astorqui's Midas cichlids is heterochronically decelerated and accompanied by malformations (Figure 1). Lagging development is also reflected in opsin gene expression, where DD individuals exhibit a later onset of expression in rods and cones (Figures 2 and 3). DD individuals exhibit rapid ontogenetic progression from a short-wavelength sensitive, typical of early ontogeny, to a long-wavelength sensitive phenotype, characteristic of 

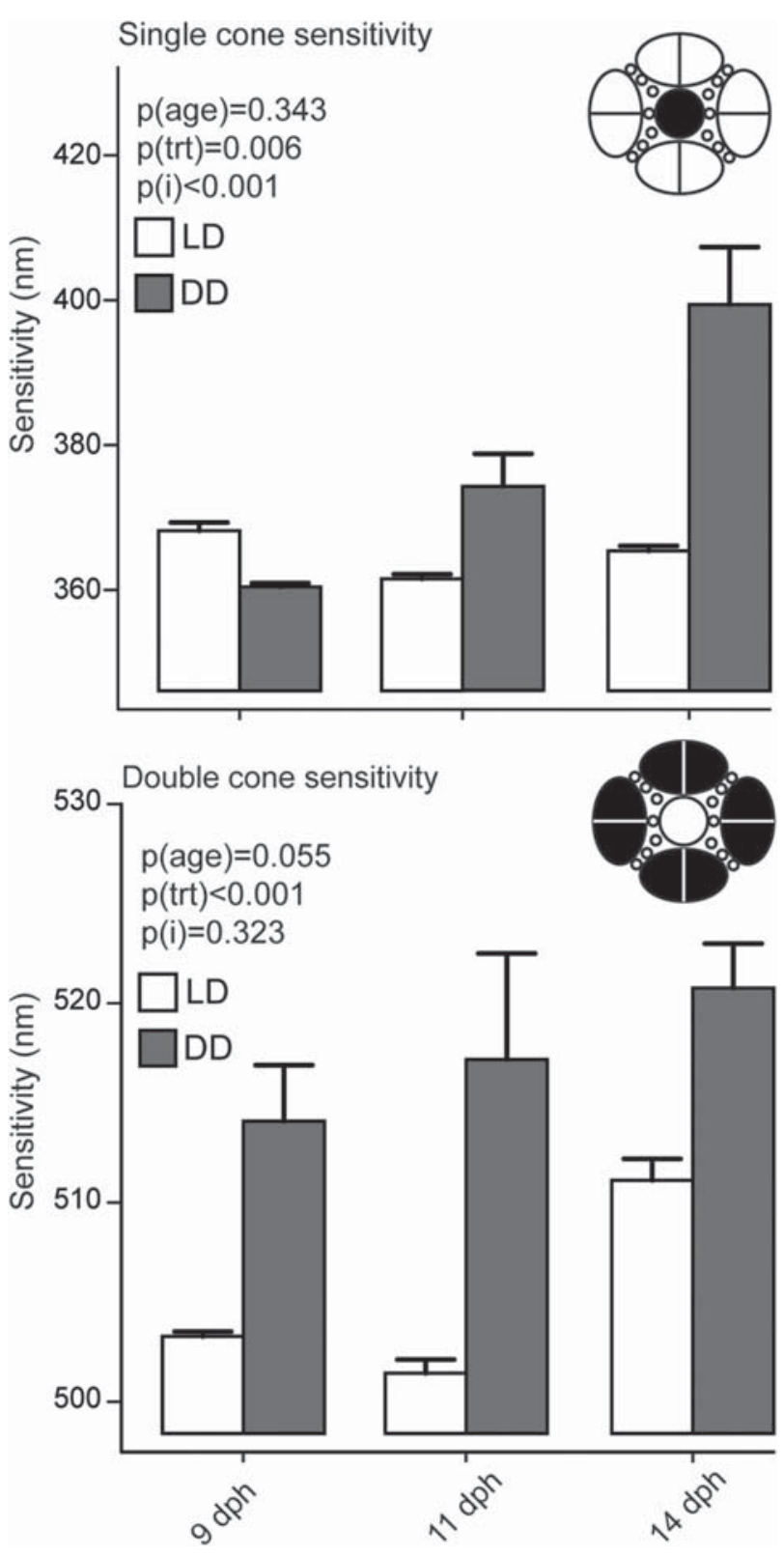

FIGURE 5 Predicted sensitivities calculated based on relative opsin gene expression and the peak of absorbance for each opsin, respectively. Predicted sensitivity for single cones (top) and for double cones (bottom). Predicted sensitivities are given as the mean and error bars represent the standard error

late ontogeny (Figures 3-5). These changes in development are correlated with a disruption of TH metabolism (Figure 6), and in agreement with previous findings on the impact of $\mathrm{TH}$ on the visual sensitivity of fish (Cheng et al., 2009; Novales Flamarique, 2013; Suliman et al., 2014).

\subsection{Development is decelerated in dark-reared Midas cichlids}

Development of DD individuals was decelerated compared with LD individuals and the developmental lag increased over time and malformations of the spine accumulated (Figure 1). Several studies on fish

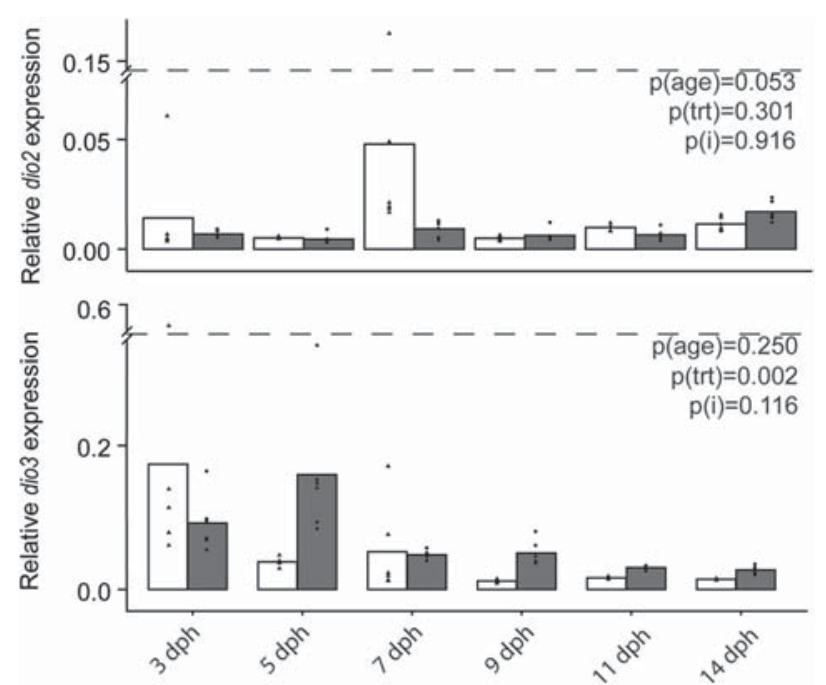

FIGURE 6 dio2 and dio3 expression patterns for LD (white bars) and DD (gray bars) Midas cichlids $(n=6)$. Individual values are given with bars indicating the median for each gene

have shown a similar lag of development when individuals are reared under reduced illumination (Bolla \& Holmefjord, 1988; Villamizar et al., 2011; Torres-Dowdall, Karagic, Plath, \& Riesch, 2018). One potential explanation for the developmental lag in Midas cichlids is the inability to capture food in the dark environment. However, the lag was evident before the open-mouth stage, which normally occurs between 3 and $4 \mathrm{dph}$ (Kratochwil et al., 2015) and before they started to be fed at $7 \mathrm{dph}$. Further, fish retain a large yolk sac until $14 \mathrm{dph}$ (Figure 1), indicating that nutrient depletion, if at all, played a small role in the observed developmental delay (Figure 1). A second potential explanation is temperature differences between light treatments, which can have an impact on developmental rates of fish (Bolla et al., 1988, Kratochwil et al., 2015; Schirone \& Gross, 1968). Temperatures between the light treatments in this study differed by $1.5^{\circ} \mathrm{C}\left(25^{\circ} \mathrm{C}\right.$ in the light treatment; $23.5^{\circ} \mathrm{C}$ in the dark treatment). However, Kratochwil et al. (2015) showed, that a temperature difference of $3^{\circ} \mathrm{C}$ during early development of Midas cichlids only produced a developmental delay of a few hours. Thus, temperature is highly unlikely to explain the strong impairment of development seen in DD fish. Further, temperature differences cannot account for the malformations arising when Midas cichlids were reared in the dark. Thus, it is improbable that temperature differences between treatments account for the extent of developmental delay observed between LD and DD individuals and for the accumulation of malformations in DD fish.

An alternative and more plausible mechanism is that dark-rearing disrupts hormonal activity. The pineal gland, a light sensing organ containing nonvisual opsins in the brain, is involved in regulating circadian rhythms and development (Davies et al., 2015; Falcón, 1999; Falcón et al., 2010; Peirson, Halford, \& Foster, 2009; Shao et al., 2017). Melatonin is secreted during the night and acts on multiple downstream targets, including thyroid follicles (Falcón et al., 2003; Falcón et al., 2010; Wright, Pikula, Cykowski, \& Kuliga, 1996), where it exerts negative effects on metabolism and growth (Baschieri et al., 1963; Wajs et al., 1989; Wright et al., 1996). Additionally, opsin genes are found 
to be involved in development through different routes. For example, Shao et al. (2017) have shown that opsin genes are involved in developmental processes via retinoic acid signaling during flounder metamorphosis. Deprivation of light and alterations in opsin expression patterns caused by changes in TH levels could, thus, interact with each other to produce disrupted development in Midas cichlids.

\subsection{Dark-rearing affects multiple characters during retinal development of Midas cichlids}

Coinciding with an overall delay in general development and eye development, the onset of opsin gene expression was delayed from $5 \mathrm{dph}$, as found in LD individuals, to $9 \mathrm{dph}$ in DD individuals (Figures 2 and 3). At this age, eye development was finally completed in DD individuals (Figure 1). The fact that opsin gene expression is only evident then suggests that the onset of opsin gene expression is associated to eye development (Figures 2 and 3), independently of ambient light, as has been shown for zebrafish (Raymond, Barthel, \& Curran, 1995).

After the onset, opsin gene expression in Astorqui's Midas cichlids normally progresses slowly during development, retaining a shortwavelength sensitive opsin set for a long time, compared to the early shift toward long-wavelength sensitivity observed in the ancestral phenotype of great Lake Midas cichlid species (Härer et al., 2017). This neoteny has probably evolved as an adaptation to the blue shifted light environment in the clear water crater lake Apoyo (Härer et al., 2017). In our experiment, LD individuals followed the same development of opsin gene expression (Figure 3). Remarkably, at $7 \mathrm{dph}$ cone opsin gene expression in LD individuals reached high levels compared to both, previous and following time points (Figure 3). Hagedorn and Fernald (1992) report that outer segments of photoreceptor cells form after five days of development. Our results are in line with previous observations made on the onset of opsin gene expression and the peak of gene expression at $7 \mathrm{dph}$ could indicate a major development and differentiation event of photoreceptor cells over the whole retina.

As Midas cichlids show adaptive developmental plasticity in opsin gene expression in response to ambient light conditions (Härer et al., 2017), we expected the dim-light vision mediating opsin rh1 and the spectrally close cone opsin rh2a to be upregulated in the dark treatment. However, rh1 and rh2a were constantly downregulated in DD individuals. Thus, the absence of light does not result in the phenotype expected based on opsin expression patterns seen in fish adapted to dim-light conditions (de Busserolles et al., 2017a; Yokoyama et al., 1999). Instead, light deprivation plastically induced a rapid progression toward a long-wavelength sensitive phenotype, characterized by expression of sws $2 b$ or sws $2 a$ in single cones and $r h 2 a$ and lws in double cones (Figure 3).

Opsin gene expression patterns in cichlid fish differ between species (e.g., Carleton et al., 2008; Escobar-Camacho, Ramos, Martins, \& Carleton, 2017; Torres-Dowdall et al., 2017; Weadick, Loew, Rodd, \& Chang, 2012; ) and during ontogeny within a species (Carleton et al., 2016; Härer et al., 2017). However, mechanisms responsible for this diversity in opsin expression are not clear yet (Carleton et al., 2016). There is evidence that changes in transcription factors govern opsin gene expression patterns (Carleton et al., 2010; O'Quin et al., 2012;
Schulte, O'Brien, Conte, O'Quin, \& Carleton, 2014; Carleton et al., 2016). A similar mechanism might be involved in plastic responses to the photic environment (i.e., depriving individuals of photic stimuli) as we observed in the Astorqui's Midas cichlids, which rapidly develop a long-wavelength sensitive phenotype, characteristic of the inferred ancestral state (e.g. Härer et al., 2017). Nandamuri, Dalton, and Carleton (2017) observed that by altering the genetic background via hybridization of two African cichlid species, they obtained offspring expressing high levels of Iws, although none of the parental species expressed Iws at high levels. Thus, altering the genetic background might have impacted regulatory networks controlling the expression of short- and long-wavelength sensitive opsin genes in the parental species. Although speculative, it is possible that the expression of the most long-wavelength sensitive opsins in cones (e.g., sws2a for single cones and Iws for double cones) represents a default state and departures from it require active processes that can be disrupted by manipulating the genetic or environmental backgrounds. Further studies would be required to determine the generality of these findings.

From in situ hybridization data of $14 \mathrm{dph}$ individuals, we observed an intriguing patterning of cone opsin gene expression (Supp. Figure 3). Replacing $r h 2 b$ as the typical opsin at the examined developmental stages, Iws seems to originate from one side of the retina and progresses further to the opposite side (Supp. Figure 3). This is in agreement with what we have previously shown in adult Astorqui's Midas cichlids (Torres-Dowdall et al., 2017). Adults of this species retain expression of $r h 2 b$ in the dorsal retina, whereas in the ventral retina only Iws and rh2a can be observed (Torres-Dowdall et al., 2017). The same patterning along a dorso-ventral gradient can be observed in the African cichlid Metriaclima zebra (Dalton, Loew, Cronin, \& Carleton, 2014). Given that cones can change their phenotype (Cheng et al., 2004), it is possible that the patterning in 14 dph Midas cichlids represents a transitional state where typical $r h 2 b$ cones are changing their spectral class to more red-sensitive Iws expressing cones.

\subsection{TH pathway as a candidate mechanism underlying the phenotypic effects in dark-reared Midas cichlids}

The disruption of TH metabolism by an increase in dio3 expression seen in DD Midas cichlids suggests it as a candidate mechanism capable of explaining the different phenotypic consequences of dark-rearing. On the one hand, $\mathrm{TH}$ is involved in numerous processes during development; while on the other hand, it is known to induce shifts in visual sensitivities toward longer-wavelengths via upregulating expression of long-wavelength sensitive and downregulating short-wavelength sensitive opsin genes (Cheng et al., 2009; Novales Flamarique, 2013; Raine et al., 2009; Suliman et al., 2014). Therefore, the disruption of the TH metabolism in DD individuals might explain the observed developmental deficiencies as well as the expression of long-wavelength sensitive opsins.

Locally, TH levels are regulated by $\mathrm{TH}$-converting deiodinases (Gereben et al., 2008a, 2008b). Deiodinase 2 (dio2) converts TH into its active $T_{3}$ form and its expression is upregulated when TH levels are low. Deiodinase 3 (dio3) inactivates $T_{3}$ and its expression is 
upregulated at high TH levels (Gereben et al., 2008a, 2008b). Comparing LD and DD Midas cichlids, we observed a disrupted pattern of expression of deiodinases in DD individuals, suggesting that $\mathrm{TH}$ metabolism might not function normally (Figure 6). LD individuals decrease dio3 expression with time until $9 \mathrm{dph}$, as maternally deposited $\mathrm{T}_{3}$ is consumed (Reddy, Brown, Leatherland, \& Lam, 1992). At $7 \mathrm{dph}$, LD Midas cichlids increase dio2 expression, which coincides with the previously described formation of thyroid follicles and the onset of endogenous TH production in cichlids (Morrison, Miyake, \& Wright, 2001; Reddy et al., 1992). In contrast, DD fish retain higher dio3 levels throughout the 14 days examined (Figure 6). Additionally, they also lack the increase in dio2 expression at $7 \mathrm{dph}$ (Figure 6), indicating that thyroid follicles might not be fully developed at this point due to alterations on photoperiodicity (Baschieri et al., 1963; Wajs et al., 1989; Wright et al., 1996). Prolonged periods of darkness or disruption of genetic signals for photoperiodicity have been shown to affect TH metabolism with correlated increases of dio3 and decreases of dio2 expression levels in different organisms (Bedolla et al., 2011, Sawant et al., 2017; Yasuo et al., 2005). We interpret the differential deiodinase expression in dark-reared Midas cichlids as evidence that TH metabolism pathways are disrupted, providing a likely explanation for the deceleration of development and the appearance of malformations. These effects have been experimentally demonstrated in zebrafish, where knocking down dio3 or applying exogenous $T_{3}$ caused delays in development and malformations (Heijlen et al., 2014). Whether dark-rearing causes higher levels of active TH, which cannot be directly measured in early stages of cichlid development, remains unanswered and needs to be addressed in further studies. However, dio2 and dio3 have been shown to be good proxies in Midas cichlids (Härer et al., 2017).

Beside overall consequences for morphological development, the disruption of $\mathrm{TH}$ metabolism has an impact on retinal development (Houbrechts et al., 2016). Disrupting TH pathways by knockdowns of dio2 or dio3 decreases the number of photoreceptors formed during development (Houbrechts et al., 2016). Although photoreceptors in retinae of DD individuals still developed, a reduced double cone density was observed (Figure 5). Thus, retinal development progresses to a point where it appears to be functional, but abnormal characters arise. However, our methods did not allow us to draw conclusions on the functionality of retinae of dark-reared fish.

Expression of long-wavelength sensitive opsins, as observed in DD individuals, is correlated with expression of dio3 (Glaschke et al., 2011; Härer et al., 2017). DD fish expressed significantly more dio3 compared with LD individuals (Figure 6). We assume that the disrupted TH metabolism with increased expression of dio3 indicates higher active TH levels in DD individuals and thus leads to a shift in visual sensitivity toward longer wavelengths (Figure 5). TH has been shown to have an effect on opsin gene expression in various teleost species (Suliman et al., 2014). In every case, application of exogenous TH induces a change in phenotype toward long-wavelength sensitivity. Midas cichlids are also susceptible to exogenous TH and increase the expression of long-wavelength sensitive opsins (Härer et al., 2017). We provide compelling evidence that a disrupted TH metabolism, likely caused by alterations of photoperiodicity important for development of thyroid follicles, underlies the phenotypic consequences we observe when rearing Midas cichlids in complete darkness.

Different species already have colonized dark environments either through possibly gradual adaptations when migrating deeper in the water column to deep-seas or through a sudden change when colonizing caves (de Busserolles et al., 2017a, 2017b; Jeffery, 2005; Tobler et al., 2010; Yokoyama et al., 1999). Especially, the second way poses significant challenges to surface-dwelling organisms. Tobler et al. (2010) have shown that within contemporary time scales evolution takes place in such a scenario, where cave-dwelling $P$. mexicana fish evolved reduced opsin expression compared to surface-dwelling sister populations. The changes in the visual system of dark-reared Midas cichlids are more complicated, including changes in onset of opsin gene expression and relative expression of different opsin genes. Taken together, it suggests that predicting the evolutionary outcome of a colonization of an aphotic environment might be challenging, given that selective pressures will be affected by a plastic response to the environment.

\section{CONCLUSIONS}

Our results indicate that light plays a vital role in the development of Midas cichlids. Potentially due to disrupted TH metabolism, the phenotype of dark-reared fish is unexpected for conditions individuals experience and their age. Despite of the decelerated overall development, ontogeny of opsin gene expression is accelerated resulting in a heterochronic shift. Light per se is not necessary to induce opsin gene expression, however, if it is present or absent strongly impacts which opsin genes are expressed across retinae.

\section{ORCID}

Nidal Karagic iD http://orcid.org/0000-0003-3575-3558

Andreas Härer (iD) http://orcid.org/0000-0003-2894-5041

Axel Meyer (iD http://orcid.org/0000-0002-0888-8193

Julián Torres-Dowdall (D) http://orcid.org/0000-0003-2729-6246

\section{REFERENCES}

Barlow, C., Pearce, M., Rodgers, L., \& Clayton, P. (1995). Effects of photoperiod on growth, survival and feeding periodicity of larval and juvenile barramundi Lates calcarifer (Bloch). Aquaculture, 138, 159-168.

Barluenga, M., Stölting, K. N., Salzburger, W., Muschick, M., \& Meyer, A. (2006). Sympatric speciation in Nicaraguan crater lake cichlid fish. Nature, 439, 719-723.

Baschieri, L., De Luca, F., Cramarossa, L., De Martino, C., Oliverio, A., \& Negri, M. (1963). Modifications of thyroid activity by melatonin. Cellular and Molecular Life Sciences, 19, 15-17.

Bedolla, D. E., \& Torre, V. (2011). A component of retinal light adaptation mediated by the thyroid hormone cascade. PLoS One, 6, e26334.

Behrmann-Godel, J., Nolte, A. W., Kreiselmaier, J., Berka, R., \& Freyhof, J. (2017). The first European cave fish. Current Biology, 27, R257-R258. 
Blas, J., Bortolotti, G. R., Tella, J. L., Baos, R., \& Marchant, T. A. (2007). Stress response during development predicts fitness in a wild, long lived vertebrate. Proceedings of the National Academy of Sciences of the United States of America, 104, 8880-8884.

Blaxter, J. H. S. (1970). Sensory deprivation and sensory input in rearing experiments. Helgoländer Wissenschaftliche Meeresuntersuchungen, 20, 642-654.

Bolla, S., \& Holmefjord, I. (1988). Effect of temperature and light on development of Atlantic halibut larvae. Aquaculture, 74, 355-358.

Busserolles, F., Marshall, J. N., \& Collin, S. P. (2014). The eyes of lanternfishes (Myctophidae, Teleostei): Novel ocular specializations for vision in dim light. Journal of Comparative Neurology, 522, 1618-1640.

Carleton, K. L., Dalton, B. E., Escobar-Camacho, D., \& Nandamuri, S. P. (2016). Proximate and ultimate causes of variable visual sensitivities: Insights from cichlid fish radiations. Genesis, 54, 299-325.

Carleton, K. L., Hofmann, C. M., Klisz, C., Patel, Z., Chircus, L. M., Simenauer, L. H., ... Ser, J. R. (2010). Genetic basis of differential opsin gene expression in cichlid fishes. Journal of Evolutionary Biology, 23, 840-853.

Carleton, K. L., \& Kocher, T. D. (2001). Cone opsin genes of African cichlid fishes: Tuning spectral sensitivity by differential gene expression. Molecular Biology and Evolution, 18, 1540-1550.

Carleton, K. L., Spady, T. C., Streelman, J. T., Kidd, M. R., McFarland, W. N., \& Loew, E. R. (2008). Visual sensitivities tuned by heterochronic shifts in opsin gene expression. BMC Biology, 6, 22

Cheng, C. L., Gan, K. J., \& Novales Flamarique, li (2009). Thyroid hormone induces a time-dependent opsin switch in the retina of salmonid fishes. Investigative Ophthalmology \& Visual Science, 50, 3024-3032.

Cheng, C. L., \& Novales Flamarique, I. (2004). Opsin expression: New mechanism for modulating colour vision. Nature, 428, 279.

Chiao, C-C., Vorobyev, M., Cronin, T. W., \& Osorio, D. (2000). Spectral tuning of dichromats to natural scenes. Vision Research, 40, 3257-3271.

Claes, J. M., Partridge, J. C., Hart, N. S., Garza-Gisholt, E., Ho, H-C., Mallefet, J., \& Collin, S. P. (2014). Photon hunting in the twilight zone: Visual features of mesopelagic bioluminescent sharks. PLoS One, 9, e104213.

Cronin, T. W., Johnsen, S., Marshall, N. J., \& Warrant, E. J. (2014). Visual ecology. Princeton, NJ: Princeton University Press.

Dalton, B. E., Loew, E. R., Cronin, T. W., \& Carleton, K. L. (2014). Spectral tuning by opsin coexpression in retinal regions that view different parts of the visual field. Proceedings of the Royal Society of London B: Biological Sciences, 281, 20141980.

Dalton, B. E., Lu, J., Leips, J., Cronin, T. W., \& Carleton, K. L. (2015). Variable light environments induce plastic spectral tuning by regional opsin coexpression in the African cichlid fish, Metriaclima zebra. Molecular Ecology, 24, 4193-4204.

Davies, W. I., Tamai, T. K., Zheng, L., Fu, J. K., Rihel, J., Foster, R. G., ... Hankins, M.W. (2015). An extended family of novel vertebrate photopigments is widely expressed and displays a diversity of function. Genome Research, 25, 1666-1679.

de Busserolles, F., Cortesi, F., Helvik, J. V., Davies, W. I., Templin, R. M., Sullivan, R. K., ... Irigoien, X. (2017a). Pushing the limits of photoreception in twilight conditions: The rod-like cone retina of the deep-sea pearlsides. Science Advances, 3, eaao4709.

de Busserolles, F., \& Marshall, J. N. (2017b). Seeing in the deep-sea: Visual adaptations in lanternfishes. Philosophical Transactions of the Royal Society B: Biological Sciences, 372, 20160070.

Escobar-Camacho, D., Ramos, E., Martins, C., \& Carleton, K. L. (2017). The opsin genes of Amazonian cichlids. Molecular Ecology, 26, 1343-1356.

Fagiolini, M., Pizzorusso, T., Berardi, N., Domenici, L., \& Maffei, L. (1994). Functional postnatal development of the rat primary visual cortex and the role of visual experience: Dark rearing and monocular deprivation. Vision Research, 34, 709-720.

Falcón, J. (1999). Cellular circadian clocks in the pineal. Progress in Neurobiology, 58, 121-162.

Falcón, J., Besseau, L., Fazzari, D., Attia, J., Gaildrat, P., Beauchaud, M., \& Boeuf, G. (2003). Melatonin modulates secretion of growth hormone and prolactin by trout pituitary glands and cells in culture. Endocrinology, 144, 4648-4658.

Falcón, J., Migaud, H., Muñoz-Cueto, J. A., \& Carrillo, M. (2010). Current knowledge on the melatonin system in teleost fish. General and Comparative Endocrinology, 165, 469-482.

Fernald, R. D. (1981). Chromatic organization of a cichlid fish retina. Vision Research, 21, 1749-1753.

Fuller, R. C., Carleton, K. L., Fadool, J. M., Spady, T. C., \& Travis, J. (2005). Genetic and environmental variation in the visual properties of bluefin killifish, Lucania goodei. Journal of Evolutionary Biology, 18, 516-523.

García-G, C., Jeziorski, M. C., Valverde-R, C., \& Orozco, A. (2004). Effects of iodothyronines on the hepatic outer-ring deiodinating pathway in killifish. General and Comparative Endocrinology, 135, 201-209.

Gereben, B., Zavacki, A. M., Ribich, S., Kim, B. W., Huang, S. A., Simonides, W. S., ... Bianco, A. C. (2008a). Cellular and molecular basis of deiodinaseregulated thyroid hormone signaling. Endocrine Reviews, 29, 898-938.

Gereben, B., Zeöld, A., Dentice, M., Salvatore, D., \& Bianco, A. C. (2008b). Activation and inactivation of thyroid hormone by deiodinases: Local action with general consequences. Cellular and Molecular Life Sciences, $65,570-590$

Ghalambor, C. K., McKay, J. K., Carroll, S. P., \& Reznick, D. N. (2007). Adaptive versus non-adaptive phenotypic plasticity and the potential for contemporary adaptation in new environments. Functional Ecology, 21, 394-407.

Gilbert, S. F. (2001). Ecological developmental biology: Developmental biology meets the real world. Developmental Biology, 233, 1-12.

Glaschke, A., Weiland, J., Turco, D., Steiner, M., Peichl, L., \& Glösmann, M. (2011). Thyroid hormone controls cone opsin expression in the retina of adult rodents. The Journal of Neuroscience, 31, 4844-4851.

Gottlieb, M. D., Fugate-Wentzek, L. A., \& Wallman, J. (1987). Different visual deprivations produce different ametropias and different eye shapes. Investigative Ophthalmology \& Visual Science, 28, 1225-1235.

Guyton, D. L., Greene, P. R., \& Scholz, R. T. (1989). Dark-rearing interference with emmetropization in the rhesus monkey. Investigative Ophthalmology \& Visual science, 30, 761-764.

Hagedorn, M., \& Fernald, R. D. (1992). Retinal growth and cell addition during embryogenesis in the teleost, Haplochromis burtoni. Journal of Comparative Neurology, 321, 193-208.

Härer, A., Torres-Dowdall, J., \& Meyer, A. (2017). Rapid adaptation to a novel light environment: The importance of ontogeny and phenotypic plasticity in shaping the visual system of Nicaraguan Midas cichlid fish (Amphilophus citrinellus spp.). Molecular Ecology, 26, 5582-5593.

Heijlen, M., Houbrechts, A. M., Bagci, E., Herck, S. L. J., Kersseboom, S. Esguerra, C. V., ... Darras, V. M. (2014). Knockdown of type 3 iodothyronine deiodinase severely perturbs both embryonic and early larval development in zebrafish. Endocrinology, 155, 1547-1559.

Hofmann, C. M., O'Quin, K. E., Marshall, N. J., Cronin, T. W., Seehausen, O., $\&$ Carleton, K. L. (2009). The eyes have it: Regulatory and structural changes both underlie cichlid visual pigment diversity. PLoS Biology, 7, e1000266.

Hofmann, C. M., O'Quin, K. E., Smith, A. R., \& Carleton, K. L. (2010). Plasticity of opsin gene expression in cichlids from Lake Malawi. Molecular Ecology, 19, 2064-2074. 
Houbrechts, A. M., Vergauwen, L., Bagci, E., Van houcke, J., Heijlen, M., Kulemeka, B., ... Darras, V. M. (2016). Deiodinase knockdown affects zebrafish eye development at the level of gene expression, morphology and function. Molecular and Cellular Endocrinology, 424, 81-93.

Hubel, D. H., \& Wiesel, T. N. (1963). Receptive fields of cells in striate cortex of very young, visually inexperienced kittens. Journal of Neurophysiol, 26, 994-1002.

Hubel, D. H., \& Wiesel, T. N. (1970). The period of susceptibility to the physiological effects of unilateral eye closure in kittens. The Journal of Physiology, 206, 419-436.

Jeffery, W. R. (2005). Adaptive evolution of eye degeneration in the Mexican blind cavefish. Journal of Heredity, 96, 185-196.

Johnson, K. M., \& Lema, S. C. (2011). Tissue-specific thyroid hormone regulation of gene transcripts encoding iodothyronine deiodinases and thyroid hormone receptors in striped parrotfish (Scarus iseri). General and Comparative Endocrinology, 172, 505-517.

Kautt, A. F., Machado-Schiaffino, G., \& Meyer, A. (2016). Multispecies outcomes of sympatric speciation after admixture with the source population in two radiations of Nicaraguan crater lake cichlids. PLOS Genetics, 12, e1006157. https://doi.org/10.1371/journal.pgen.1006157.

Kratochwil, C. F., Sefton, M. M., \& Meyer, A. (2015). Embryonic and larval development in the Midas cichlid fish species flock (Amphilophus spp.): A new evo-devo model for the investigation of adaptive novelties and species differences. BMC Developmental Biology, 15

Kröger, R. H., \& Fernald, R. D. (1994). Regulation of eye growth in the African cichlid fish Haplochromis burtoni. Vision Research, 34, 1807-1814.

Langecker, T. G., Schmale, H., \& Wilkens, H. (1993). Transcription of the opsin gene in degenerate eyes of cave-dwelling Astyanax fasciatus (Teleostei, Characidae) and of its conspecific epigean ancestor during early ontogeny. Cell and Tissue Research, 273, 183-192.

Levine, J., MacNichol, E., Kraft, T., \& Collins, B. (1979). Intraretinal distribution of cone pigments in certain teleost fishes. Science, 204, 523526.

Liu, H. W., Stickney, R. R., Dickhoff, W. W., \& McCaughran, D. A. (1994). Effects of environmental factors on egg development and hatching of Pacific halibut Hippoglossus stenolepis. Journal of the World Aquaculture Society, 25, 317-321.

Marlatt, V. L., Gerrie, E., Wiens, S., Jackson, F., Moon, T. W., \& Trudeau, V. L. (2012). Estradiol and triiodothyronine differentially modulate reproductive and thyroidal genes in male goldfish. Fish Physiology and Biochemistry, 38, 283-296.

Martino, E., Seo, H., Lernmark, A., \& Refetoff, S. (1980). Ontogenetic patterns of thyrotropin-releasing hormone-like material in rat hypothalamus, pancreas, and retina: Selective effect of light deprivation. Proceedings of the National Academy of Sciences, 77, 4345-4348.

Mielke, P. W., Berry, K. J., Brockwell, P. J., \& Williams, J. S. (1981). A class of nonparametric tests based on multiresponse permutation procedures. Biometrika, 68, 720-724.

Morrison, C. M., Miyake, T., \& Wright, J. R. (2001). Histological study of the development of the embryo and early larva of Oreochromis niloticus (Pisces: Cichlidae). Journal of Morphology, 24, 172-195.

Nagai, H., Terai, Y., Sugawara, T., Imai, H., Nishihara, H., Hori, M., \& Okada, N. (2010). Reverse evolution in RH1 for adaptation of cichlids to water depth in Lake Tanganyika. Molecular Biology and Evolution, 28, 17691776.

Nandamuri, S. P., Dalton, B. E., \& Carleton, K. L. (2017). Determination of the genetic architecture underlying short wavelength sensitivity in Lake Malawi cichlids. Journal of Heredity, 108, 379-390.

Ng, L., Hurley, J. B., Dierks, B., Srinivas, M., Saltó, C., Vennström, B., ... Forrest, D. (2001). A thyroid hormone receptor that is required for the development of green cone photoreceptors. Nature genetics, 27, 94-98.

Niemiller, M. L., Fitzpatrick, B. M., Shah, P., Schmitz, L., \& Near, T. J. (2013). Evidence for repeated loss of selective constraint in rhodopsin of amblyopsid cavefishes (Teleostei: Amblyopsidae). Evolution, 67, 732-748.

Norton, T. T., Amedo, A. O., \& Siegwart, J. T. (2006). Darkness causes myopia in visually experienced tree shrews. Investigative Ophthalmology \& Visual Science, 47, 4700-4707.

Novales Flamarique, I. (2013). Opsin switch reveals function of the ultraviolet cone in fish foraging. Proceedings of the Royal Society of London B: Biological Sciences, 280, 20122490.

O'Quin, K. E., Smith, A. R., Sharma, A., \& Carleton, K. L. (2011a). New evidence for the role of heterochrony in the repeated evolution of cichlid opsin expression. Evolution \& Development, 13, 193-203.

O'Quin, K. E., Smith, D., Naseer, Z., Schulte, J., Engel, S. D., Loh, Y-H. E., ... Carleton, K. L. (2011b). Divergence in cis-regulatory sequences surrounding the opsin gene arrays of African cichlid fishes. BMC Evolutionary Biology, 11, 120.

O'Quin, K. E., Schulte, J. E., Patel, Z., Kahn, N., Naseer, Z., Wang, H., ... Carleton, K. L. (2012). Evolution of cichlid vision via trans-regulatory divergence. BMC Evolutionary Biology, 12, 1-11.

Peirson, S. N., Halford, S., \& Foster, R. G. (2009). The evolution of irradiance detection: Melanopsin and the non-visual opsins. Philosophical Transactions of the Royal Society B: Biological Sciences, 364, 2849-2865.

Pointer, M. A., Carvalho, L. S., Cowing, J. A., Bowmaker, J. K., \& Hunt, D. M. (2007). The visual pigments of a deep-sea teleost, the pearl eye Scopelarchus analis. Journal of Experimental Biology, 210, 2829-2835.

Raine, J. C., \& Hawryshyn, C. W. (2009). Changes in thyroid hormone reception precede SWS1 opsin downregulation in trout retina. Journal of Experimental Biology, 212, 2781-2788.

Raymond, P. A., Barthel, L. K., \& Curran, G. A. (1995). Developmental patterning of rod and cone photoreceptors in embryonic zebrafish. Journal of Comparative Neurology, 359, 537-550.

Reddy, P. K., Brown, C. L., Leatherland, J. F., \& Lam, T. J. (1992). Role of thyroid hormones in tilapia larvae (Oreochromis mossambicus): II. Changes in the hormones and $5^{\prime}$-monodeiodinase activity during development. Fish Physiology and Biochemistry, 9, 487-496.

Rennison, D. J., Owens, G. L., \& Taylor, J. S. (2012). Opsin gene duplication and divergence in ray-finned fish. Molecular Phylogenetics and Evolution, 62, 986-1008.

Roberts, M. R., Srinivas, M., Forrest, D., de Escobar, G. M., \& Reh, T. A. (2006). Making the gradient: Thyroid hormone regulates cone opsin expression in the developing mouse retina. Proceedings of the National Academy of Sciences, 103, 6218-6223.

Rutherford, S. L. (2000). From genotype to phenotype: Buffering mechanisms and the storage of genetic information. Bioessays, 22, 1095-1105.

Sakai, Y., Ohtsuki, H., Kasagi, S., Kawamura, S., \& Kawata, M. (2016). Effects of light environment during growth on the expression of cone opsin genes and behavioral spectral sensitivities in guppies (Poecilia reticulata). BMC Evolutionary Biology, 16, 106.

Sawant, O. B., Horton, A. M., Zucaro, O. F., Chan, R., Bonilha, V. L., Samuels, I. S., \& Rao, S. (2017). The circadian clock gene Bmal1 controls thyroid hormone-mediated spectral identity and cone photoreceptor function. Cell Reports, 21, 692-706.

Scheirer, C. J., Ray, W. S., \& Hare, N. (1976). The analysis of ranked data derived from completely randomized factorial designs. Biometrics, 32, 429-434.

Schirone, R. C., \& Gross, L. (1968). Effect of temperature on early embryological development of the zebra fish, Brachydanio rerio. Journal of 
Experimental Zoology Part A: Ecological and Integrative Physiology, 169, 43-52.

Schobert, C. S., Stiassny, M. L., Schwab, I. R., Zeiss, C., Schelly, R. C., \& Dubielzig, R. R. (2013). Comparative ocular anatomy in a blind African cichlid fish, Lamprologus lethops. Veterinary Ophthalmology, 16, 359364.

Schulte, J. E., O'Brien, C. S., Conte, M. A., O'Quin, K. E., \& Carleton, K. L. (2014). Interspecific variation in Rx1 expression controls opsin expression and causes visual system diversity in African cichlid fishes. Molecular Biology and Evolution, 31, 2297-2308.

Shao, C., Bao, B., Xie, Z., Chen, X., Li, B., Jia, X., ... Li, X. (2017). The genome and transcriptome of Japanese flounder provide insights into flatfish asymmetry. Nature Genetics, 49, 119-124.

Siegal, M. L., \& Bergman, A. (2002). Waddington's canalization revisited: Developmental stability and evolution. Proceedings of the National Academy of Sciences, 99, 10528-10532.

Spady, T. C., Parry, J. W., Robinson, P. R., Hunt, D. M., Bowmaker, J. K., \& Carleton, K. L. (2006). Evolution of the cichlid visual palette through ontogenetic subfunctionalization of the opsin gene arrays. Molecular Biology and Evolution, 23, 1538-1547.

Sugawara, T., Imai, H., Nikaido, M., Imamoto, Y., \& Okada, N. (2010). Vertebrate rhodopsin adaptation to dim light via rapid meta-II intermediate formation. Molecular Biology and Evolution, 27, 506-519.

Sugawara, T., Terai, Y., Imai, H., Turner, G. F., Koblmüller, S., Sturmbauer, C., ... Okada, N. (2005). Parallelism of amino acid changes at the RH1 affecting spectral sensitivity among deep-water cichlids from Lakes Tanganyika and Malawi. Proceedings of the National Academy of Sciences of the United States of America, 102, 5448-5453.

Suliman, T., \& Novales Flamarique, I. (2014). Visual pigments and opsin expression in the juveniles of three species of fish (rainbow trout, zebrafish, and killifish) following prolonged exposure to thyroid hormone or retinoic acid. Journal of Comparative Neurology, 522, 98117

Tobler, M., Coleman, S. W., Perkins, B. D., \& Rosenthal, G. G. (2010). Reduced opsin gene expression in a cave-dwelling fish. Biology Letters, 6, 98-101.

Torres-Dowdall, J., Karagic, N., Plath, M., \& Riesch, R. (2018). Evolution in caves: Selection from darkness causes spinal deformations in teleost fish. Biology Letters, 20180197. https://doi.org/10.1098/rsbl.2018.0197

Torres-Dowdall, J., Pierotti, M. E., Härer, A., Karagic, N., Woltering, J. M., Henning, F., ... Meyer, A. (2017). Rapid and parallel adaptive evolution of the visual system of Neotropical Midas cichlid fishes. Molecular Biology and Evolution, 34, 2469-2485.

Trotter, A., Battaglene, S., \& Pankhurst, P. (2003). Effects of photoperiod and light intensity on initial swim bladder inflation, growth and postinflation viability in cultured striped trumpeter (Latris lineata) larvae. Aquaculture, 224, 141-158.

Villamizar, N., Blanco-Vives, B., Migaud, H., Davie, A., Carboni, S., \& SánchezVázquez, F. J. (2011). Effects of light during early larval development of some aquacultured teleosts: A review. Aquaculture, 315, 86-94.

Villamizar, N., García-Alcazar, A., \& Sánchez-Vázquez, F. J. (2009). Effect of light spectrum and photoperiod on the growth, development and survival of European sea bass (Dicentrarchus labrax) larvae. Aquaculture, 292, 80-86.

Wagner, H-J., \& Kröger, R. H. (2005). Adaptive plasticity during the development of colour vision. Progress in Retinal and Eye Research, 24, 521-536.
Wajs, E., Krotewicz, M., Fryczak, J., Kulak, J., Sewerynek, E., Szkudlinski, M., \& Lewinski, A. (1989). Melatonin suppresses the pinealectomy-induced increase of mitotic incidence in the rat thyroid gland. Medical Science Research, 17, 61-62.

Wald, G. (1968). The molecular basis of visual excitation. Nature, 219, 800 807.

Walpita, C. N., Crawford, A. D., Janssens, E. D. R., der Geyten, S., \& Darras, V. M. (2009). Type 2 iodothyronine deiodinase is essential for thyroid hormone-dependent embryonic development and pigmentation in zebrafish. Endocrinology, 150, 530-539.

Weadick, C. J., Loew, E. R., Rodd, H. F., \& Chang, B. S. W. (2012). Visual pigment molecular evolution in the Trinidadian pike cichlid (Crenicichla frenata): A less colorful world for Neotropical cichlids? Molecular Biology and Evolution, 29, 3045-3060.

West-Eberhard, M. J. (2003). Developmental plasticity and evolution. Oxford, England; New York: Oxford University Press.

Wiesel, T. N., \& Hubel, D. H. (1963). Effects of visual deprivation on morphology and physiology of cells in the cat's lateral geniculate body. Journal of Neurophysiology, 26, 978-993.

Wilkens, H., Strecker, U., \& Yager, J. (1989). Eye reduction and phylogenetic age in ophidiiform cave fish. Journal of Zoological Systematics and Evolutionary Research, 27, 126-134

Woltering, J. M., Vonk, F. J., Müller, H., Bardine, N., Tuduce, I. L., de Bakker, M. A., ... Richardson, M. K. (2009). Axial patterning in snakes and caecilians: Evidence for an alternative interpretation of the Hox code. Developmental Biology, 332, 82-89.

Wright, M. L., Pikula, A., Cykowski, L. J., \& Kuliga, K. (1996). Effect of melatonin on the anuran thyroid gland: Follicle cell proliferation, morphometry, and subsequent thyroid hormone secretion in vitro after melatonin treatment in vivo. General and Comparative Endocrinology, 103, 182-191.

Yasuo, S., Watanabe, M., Nakao, N., Takagi, T., Follett, B. K., Ebihara, S., \& Yoshimura, T. (2005). The reciprocal switching of two thyroid hormoneactivating and -inactivating enzyme genes is involved in the photoperiodic gonadal response of Japanese Quail. Endocrinology, 146, 2551 2554.

Yokoyama, S. (2008). Evolution of dim-light and color vision pigments. Annual Reviews of Genomics and Human Genetics, 9, 259-282.

Yokoyama, S., Zhang, H., Radlwimmer, F. B., \& Blow, N. S. (1999). Adaptive evolution of color vision of the Comoran coelacanth (Latimeria chalumnae). Proceedings of the National Academy of Sciences of the United States of America, 96, 6279-6284. 